\title{
EVALUATING FATIGUE BEHAVIOR OF ASPHALT BINDERS AND MIXES CONTAINING DATE SEED ASH
}

\author{
Ali FOROUTAN MIRHOSSEINI ${ }^{\mathrm{a}}$, Amir KAVUSSI ${ }^{\mathrm{b}}$, Mohammad Hossain JALAL KAMALI ${ }^{\mathrm{b}}$, \\ Mohammad Mehdi KHABIRI ${ }^{c}$, Abolfazl HASSANI ${ }^{b}$ \\ ${ }^{a}$ Department of Civil and Environmental Eng., Norwegian University of Science and Technology, \\ Trondheim, Norway \\ ${ }^{b}$ Civil and Environmental Engineering Department, Tarbiat Modares University, Tehran, Iran \\ ${ }^{c}$ Civil Engineering Department, Yazd University, Yazd, Iran
}

Received 07 May 2017; accepted 15 Oct 2017

\begin{abstract}
Fatigue is one of the most occurring distresses in asphalt pavements. Asphalt binder plays a critical role in fatigue behavior of asphalt mixes. Modelling and predicting fatigue behavior of binders will result in more fatigue resistant mixes. In this research, possibility of using Date Seed Ash alongside two commonly used additives (namely, a siliceous and a limestone) as bitumen modifier were investigated. Then, the influence of these additives on fatigue behavior of asphalt binders and mixes was investigated. Linear Amplitude Sweep (LAS) test was carried out and Viscoelastic Continuum Damage (VECD) parameter was determined. In addition, Indirect Tensile Fatigue Test (ITFT) was performed on mixes containing these additives. Correlation equations were developed to link fatigue behavior of binders to those of mixes. The results showed acceptable agreement between binders and mixes fatigue testing results. In addition, with predicted models it was able to obtain the asphalt binders contribution to mixes fatigue resistance. However, in the case of ash modified samples, no good correlation was observed between fatigue behavior of binders and that of mixes.
\end{abstract}

Keywords: date seed ash (DSA), linear amplitude sweep (LAS), viscoelastic continuum damage (VECD), indirect tensile stiffness modulus (ITSM), indirect tensile fatigue test (ITFT), hot mix asphalt (HMA).

\section{Introduction}

Fatigue failure in asphalt mixes occurs as a result of accumulation of damages under repeated loading. Fatigue cracking resistance of asphalt pavements is highly dependent on pavement layers thicknesses, mix volumetrics, mixture type and the structure of the pavement (Safaei et al. 2016). Several tests are carried out to evaluate fatigue behavior of asphalt mixes, including Flexural Fatigue Beam and Indirect Tensile Fatigue Tests (ITFT). It is recommended to perform fatigue testing on bituminous mixes at intermediate ambient temperatures (e.g. $20^{\circ} \mathrm{C}$ ) (Modarres 2013). Experimental assessment of cracks implies that fatigue cracking occurs through the binder phase and will be spread to the whole mix (Safaei et al. 2014). As asphalt binder plays a key role in fatigue behavior of asphalt mixtures, many researchers investigated the application of additives in order to improve characteristics of binders in mixes (Khattak et al. 2013; Capitão et al. 2012; Yang et al. 2014). It would be reasonable to utilize both an experimental method alongside with a theoretical model to predict how binders and mixes behave under traffic loading and resist fatigue cracking.
Although the currently applied performance grade specifications of asphalt fatigue resistance (that is based on linear viscoelastic behavior) is adequate for evaluating the overall quality of the binders, the main defect is their inapplicability in characterizing the actual damage resistance of mixes (Hintz, Bahia 2013; Deacon et al. 1997; Bahia et al. 2001a, 2001b). Furthermore, this grading system cannot be used to characterize modified binders, precisely. Many researchers have criticized the $\mathrm{G}^{*}$ Sin parameter (known as fatigue crack parameter), which is the stiffness-based parameter measured in a quite different condition than that in the field (Deacon et al. 1997; Bahia et al. 2001b; Andriescu et al. 2004; Tsai et al. 2005). Fixed frequency, few cycles of loading and small shearing strain are among the restricted parameters in which G*Sin is measured (Zhou et al. 2012).

Viscoelastic Continuum Damage (VECD) Model is a prevalent approach which has been utilized by many researchers to evaluate fatigue resistance of asphalt mixes (Lee, Kim 1998; Daniel, Kim 2002; Kutay et al. 2008; Underwood et al. 2010; Sabouri, Kim 2014; Norouzi,

Corresponding author: Mohammad Hossain Jalal Kamali

E-mail:m.jalalkamali@gmail.com 
Kim 2015). This method is used to differentiate damage from time effects related to viscoelasticity by substituting strain with pseudo-strain (Hintz et al. 2011a). VECD Model has been simplified (namely, S-VECD) and produced on the basis of uniaxial cyclic direct tension test to predict fatigue life of asphalt pavements (Norouzi, Kim 2015; Schapery 1990). This method, then, became a standard procedure and was known as AASHTO TP-107. Recently, VECD modeling method has been applied to binders (Safaei et al. 2014; Hintz et al. 2011b). Johnson et al. (2009) evaluated the application of VECD method under monotonic constant strain-rate shear loading by DSR which was proposed by Wen and Bahia and demonstrated the inapplicability of this approach for polymermodified binders.

Thereafter, he applied VECD model on asphalt binders and subjected these to a cyclic loading in DSR testing. Then, Johnson et al. (2009) presented the Linear Amplitude Sweep (LAS) test. Others improved the test by recommending continuous increment in amplitude sweep instead of the stepwise case (Hintz, Bahia 2013). This testing method was then standardized in AASHTO TP-101 (2014). Currently the LAS test seems to be the most accurate testing method in predicting bituminous binders fatigue behavior. However, Hintz and Bahia (2013) recommended that it would be better name it a damage tolerance test rather than a fatigue testing.

On the other hand, the application of different additives in bituminous mixes has been widely investigated. These include diverse categories such as polymers, fibers, industrial by-products, waste materials, nanomaterials, catalysts, engineered and natural materials (Whiteoak 1990; Arabani et al. 2017a). Among these, Polymer Modified Bitumens (PMBs) are the most widely in high performance mixes (Yildirim 2007). Investigations showed that a single PMB is not able to address all the pavement distresses (e.g. rutting, fatigue cracking, moisture damage and age hardening of mixes lonely) (Read, Whiteoak 2003; Chen et al. 2002; Kavussi, Barghabany 2015; Isacsson, Xiaohu 1999). In this study, the feasibility of using Date Seed Ash (DSA) as a bitumen modifier to improve fatigue behavior of bitumen was investigated. Date palm grows in vast areas of the earth, particularly from North Africa to Persian Gulf. Date tree has various byproducts which are dropped into the river or deposited in the farmlands or in most of the cases they will be burnt by the farmers (Chandrasekaran, Bahkali 2013). All the mentioned issues are definitely harmful for human and environment. According to FAO annual reports, Date palm seeds, by-products of date palm tree, constitute about 2 million tons of waste materials that their proper application could be beneficial to the environment (Food F.A.O. 2015).

In this research, bitumen was modified with DSA alongside with two types of commonly used additives in asphalt pavement industry (namely, a siliceous and a limestone). The modified binders were then used to pre- pare asphalt mixtures. The first objective of this research was to produce DSA from seeds of date tree. The second and main goal of this study was to investigate whether this additive could improve the fatigue behavior of asphalt binders. LAS testing was used to analyze Viscoelastic Continuum Damage properties of the materials. Third, fatigue behavior of asphalt mixtures, containing three types of additives, were assessed applying ITFT method and finally, prediction models were developed to model fatigue behavior of bitumen and asphalt mixes.

\section{Background}

\subsection{Linear amplitude sweep test}

The current PG specifications that assess fatigue resistance of asphalt binders lack the ability of defining real damage resistance. Therefore, VECD approach cannot be applied to these testing results. In order to improve PG specifications, Time Sweep test (TS) which is performed using DSR device was introduced in NCHRP Project 9-10. This is different than the SHRP proposed PG tests that consist of applying repeated cyclic loading at fixed amplitude mode in either stress or strain controlled conditions (Safaei et al. 2016; Bahia et al. 2001a; Martona, Bahia 2008; Hintz et al. 2011a). The main problem of Time Sweep test is its rather long testing time. In some cases, testing time takes several hours until the fatigue damage occurs (Hintz, Bahia 2013). The efforts in determining fatigue resistance of binders resulted in two tests; namely Binder Yield Energy Test (BYET) which is a monotonic shear test, performed under constant strain rate loading condition and Linear Amplitude Sweep test (LAS) (Hintz et al. 2011a; AASHTO-TP101 2014). It has been proved that LAS test is more practical and appropriate for prediction of fatigue behavior of asphalt binders. Both RTFO and PAV aged binders can be tested under LAS testing. LAS and TS have some similarities in which both can be applied in DSR device using the 8-mm-diameter parallel plate geometry with 2-mm gap setting (AASHTO-TP101 2014). However, in order to accelerate damage accumulation, LAS test consists of oscillatory strain amplitude sweep in which loading amplitudes are linearly increased. In order to utilize VECD analysis, a frequency sweep test should be performed before the strain sweep, in order to determine "alpha" damage parameter. While frequency sweep is a non-damage test, the amplitude sweep test can run directly after the frequency sweep (Hintz, Bahia 2013; AASHTO-TP101 2014). It should be noted that, frequency sweep testing conditions consists of applying a load at $0.1 \%$ percent strain level over a range of $0.2-30 \mathrm{~Hz}$. More details of this test can be found elsewhere. As mentioned before, amplitude or strain sweep runs after the frequency sweep, where loading begins and increases linearly with 100 cycles at a rate of $1 \%$ increased and the application of stress until 30\% strain level is achieved as shown in Figure 1 (Safaei et al. 2016; Hintz, Bahia 2013; AASHTO-TP101 2014). 


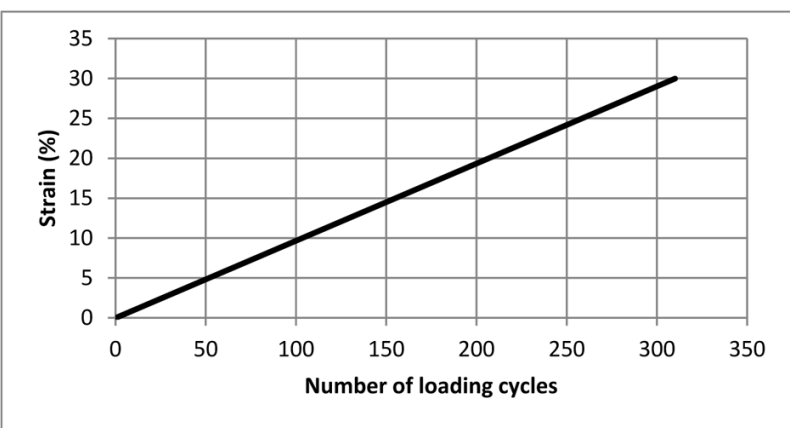

Fig. 1. Loading scheme in linear amplitude sweep test

\subsection{VECD modeling approach}

Results from LAS test can be used in VECD modeling framework. A brief review is implied herein and more details can be found elsewhere (AASHTO-TP101 2014). As mentioned before, frequency sweep should be performed to determine alpha parameter of undamaged asphalt binder. Thereafter, calculations should be carried out to develop storage modulus from the following equation:

$$
G_{(\omega)}^{\prime}=\left|G^{*}\right|_{(\omega)} \times \cos \delta_{(\omega)} .
$$

In this equation, $G_{(\omega)}^{\prime}$ is storage modulus and $\left|G^{*}\right|_{(\omega)}$ and $\delta_{(\omega)}$ are dynamic modulus and phase angle respectively. A diagram is then plotted in that $\log G_{(\omega)}^{\prime}$ and $\log \omega$ are the vertical and horizontal axis, respectively. From the above the following equation can be obtained:

$$
\log G_{(\omega)}^{\prime}=m(\log \omega)+b .
$$

The $m$ value in the above equation is used to determine $\alpha$ as it follows:

$$
\alpha=1 / m \text {. }
$$

Results from LAS testing could be utilized in Eqn (4), known as damage accumulation equation:

$$
D_{(t)} \cong \sum_{i=1}^{N}\left[\pi \gamma_{0}^{2}\left(C_{i-1}-C_{i}\right)\right]^{\frac{\alpha}{\alpha+1}}\left(t_{i}-t_{i-1}\right)^{\frac{1}{\alpha+1}}
$$

In this equation, $C$ is pseudo-stiffness and indicates material integrity. It is considered to be 1 for a material which behaves in a viscoelastic manner (Safaei et al. 2016). $C_{(t)}$, determined from Eqn (5), is a function obtained from dividing $\left|G^{*}\right|$ at time $t$, to the initial value of $\left|G^{*}\right| ; \gamma_{0}$ represents percent of applied stress for a given data point and $\left|G^{*}\right|$ stands for complex shear modulus:

$$
C_{(t)}=\frac{\left|G^{*}\right|_{(t)}}{\left|G^{*}\right|_{\text {intial }}} \text {. }
$$

As it can be seen from Eqn (4), the damage induced is a function of time which is achieved by summing $D_{(t)}$ from the beginning $(t=0)$ to the final data point. Simi- larly, $C_{(t)}$ is calculated applying the same approach. From previous works it is presumed that $C_{(t)}$ at $D_{(0)}$ is equal to 1 and $D_{(0)}$ is considered to be zero (AASHTOTP101 2014). Therefore, the relationship between $C_{(t)}$ and $D_{(t)}$ can be achieved on the basis of the power law from Eqn (6) below:

$$
C_{(t)}=C_{0}-C_{1}(D)^{C_{2}},
$$

where: $C_{1}$ and $C_{2}$ are the coefficients derived from linearization of power law equation as it follows:

$$
\log \left(C_{0}-C_{(t)}\right)=\log \left(C_{1}\right)+C_{2} \times \log \left(D_{(t)}\right) .
$$

Reduction in initial $\left|G^{*}\right|$ at the peak shear stress represents failure point and $D_{(t)}$ corresponding with this point is known as $D_{f}$ determined from the following equation:

$$
D_{f}=\left(\frac{C_{0}-C_{a t \text { Peak Stress }}}{C_{1}}\right)^{\frac{1}{C_{2}}} .
$$

The binder fatigue performance could be calculated using Eqn (9) below:

$$
N_{f}=A\left(\gamma_{\max }\right)^{-B},
$$

where $\gamma_{\max }$ is the percentage of maximum expected binder strain for a given pavement structure. Indexes $A$ and $B$ are fatigue performance parameters, calculated from Eqn (10) below:

$$
A=\frac{f\left(D_{f}\right)^{k}}{k\left(\pi C_{1} C_{2}\right)^{\alpha}}
$$

where: $f=$ Loading frequency $(10 \mathrm{~Hz}) ; k=1+\left(1-C_{2}\right) \alpha$, and $B=2 \alpha$.

\subsection{Indirect tensile stiffness modulus}

Indirect tensile stiffness modulus test is a non-destructive test, used to determine stiffness of asphalt mixes. Stiffness modulus $\left(S_{m}\right)$ is one of the key parameters in asphalt mix analysis, playing a major role in their fatigue behavior. $S_{m}$ is an important value that shows the ability of asphalt mixes to tolerate stress and strains due to repeated traffic loading (Arabani et al. 2017b). In this research, ITSM testing was carried according to AASHTOTP31 (1996) procedure using a Universal Testing Machine (UTM-14). Specimens were subjected to haversine loading pulses across the vertical axis of each specimen. Figure 2 shows a typical loading scheme of UTM device in ITSM testing in which horizontal deformation is plotted against time. This is measured via three Linear Variable Differential Transducers (LDVTs) attached to the front and back sides of the specimen. All the tests were conducted at $20^{\circ} \mathrm{C}$. Three specimens were prepared for each mix composition and each specimen was tested twice (rotating $180^{\circ}$ around $\mathrm{x}$-axis). 


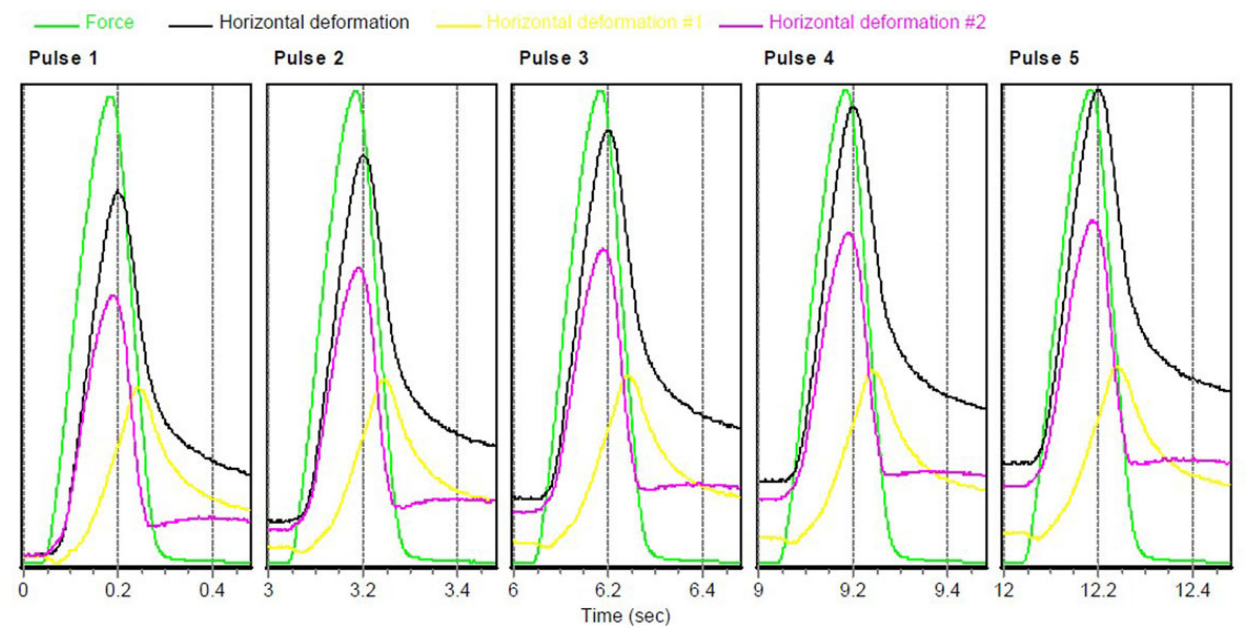

Fig. 2. Loading scheme in ITSM test

UTM device used in this research automatically calculates the stiffness modulus values of the specimens. Stiffness modulus could be determined from the following equation:

$$
S_{m}=\frac{P(v+0.27)}{t \times H} .
$$

In this equation, $S_{m}$ is stiffness modulus (MPa), $P$ is the maximum dynamic load $(\mathrm{N}), t$ is average thickness of the specimen, $H$ is horizontal deformation and $v$ is Poisson ratio (assumed to be 0.35 ).

\subsection{Indirect tensile fatigue test}

Fatigue cracking in asphalt pavements usually occur due to repeated loadings (Al-Khateeb, Shenoy 2004; Martona, Bahia 2003). Indirect tensile fatigue test (ITFT) is one of the most efficient tests which is designed to predict fatigue behavior of asphalt mixes. The greater resistance of mixes to fatigue results in fewer fatigue cracks (Arabani et al. 2017b). ITFT can be conducted either in strain or stress controlled modes (Arabani, Mirabdolazimi 2011). In this research, the test was conducted in stress controlled mode, according to EN-12697-24 (2004). Failure of the specimens occurred when either the specimen completely fractured or the vertical deformation reached $9 \mathrm{~mm}$ and the fatigue life was determined as the total number of loads that caused failure in the specimen (EN12697-24 2004). The test was carried out at the fixed temperature of $20^{\circ} \mathrm{C}$ and at three stress levels of 150,250 and $400 \mathrm{kPa}$. Haversine loading was applied during the test with $500 \mathrm{~ms}$ repetition time and $100 \mathrm{~ms}$ pulse widths.

It has been proved that fatigue cracks at the bottom of the asphalt layer are mainly created due to the concentration of tensile stresses caused by traffic loading (Arabani et al. 2017b). As a result, tensile strain at the bottom of the mix is directly related to the number of cycles to failure. As tensile strain of the specimen for each level of stress is given, a relationship between number of loading cycles to failure and tensile strain of the specimen can be determined. Several models are developed to predict fatigue life of asphalt mixes, based on regression analysis of the results. Among these, Wohler's Model is a simple model which is widely accepted and is utilized by researchers (Arabani et al. 2017b; Shafabakhsh et al. 2015; Sybilski, Bańkowski 2002; Azarhoosh et al. 2016). This model, defined in Eqn (12), was used in this research:

$$
N_{f}=a\left(\frac{1}{\varepsilon_{t}}\right)^{b} .
$$

In this equation $N_{f}$ is the number of load cycles to failure, $\varepsilon_{t}$ is the applied strain, and $a$ and $b$ are regression coefficients.

\section{Materials, mix design and procedure}

A PG 58-22 bitumen from Isfahan Refinery was used in this research. In order to prepare the modified binders, three types of additives were added to bitumen at three different levels of $3 \%, 6 \%$ and $9 \%$. The mixing procedure was prepared applying two steps as recommended by some researches (Cuadri et al. 2015; Köfteci et al. 2014). Firstly, the bitumen was heated to $160{ }^{\circ} \mathrm{C}$ and DSA as other additives was poured slowly into the mixing container. Mixing was continued for 10 to 15 minutes at $600 \mathrm{rpm}$. Second, in order to achieve better homogenous mixtures, mixing speed was increased to $2000 \mathrm{rpm}$ and mixing was kept on for one hour. For simplicity, samples were named with two letters and a number. With this regard, B represents bitumen and the next letter indicates the type of additive. The numbers show the percentages of additive by weight of bitumen. For example, BD3 represents binder with 3\% DSA (by weight of bitumen). Similarly, BS and BL represent bitumen modified with siliceous and limestone additives, respectively. Then, the modified bitumen samples were added to the aggregates in order to prepare asphalt mixes. It is to be mentioned that limestone aggregate was utilized to prepare all of the hot mix asphalt samples according to ASTM D6927 standard and optimum bitumen content was determined for control sample (with no bitumen additive) and it was 
employed for other mixes. Asphalt mixes gradation was based on the continuous type IV scale of the AASHTO (1993) and is depicted in Table 1 (AASHTO 1993).

Table 1. Gradation of aggregates used in the study

\begin{tabular}{l|c|c|c|c|c|c}
\hline $\begin{array}{c}\text { Sieve } \\
(\mathrm{mm})\end{array}$ & 19 & 12.5 & 4.75 & 2.36 & 0.3 & 0.075 \\
\hline $\begin{array}{l}\text { Lower- } \\
\text { upper limit }\end{array}$ & 100 & $90-100$ & $74-77$ & $28-58$ & $5-21$ & $2-10$ \\
$\begin{array}{l}\text { Passing } \\
(\%)\end{array}$ & 100 & 95 & 59 & 43 & 13 & 6 \\
\hline
\end{tabular}

\subsection{Production of DSA}

The Date Seed Ash that was used in this research, was prepared in two phases. The first phase consisted of burning Date Palm Seeds in order to convert these into date seed coal. In the second phase, the date seed coal was placed in a furnace and was heated to 600 to $800{ }^{\circ} \mathrm{C}$ for 1.5 to 2 hours (Mirhosseini et al. 2016). Figure 3 shows a sample of DSA that has gray color. As some unburned and rather coarse black particles were observed, the ash was sieved on a No. 200 Sieve. In order to have additives with the same maximum size, siliceous and limestone additives were also passed through Sieve No. 200.

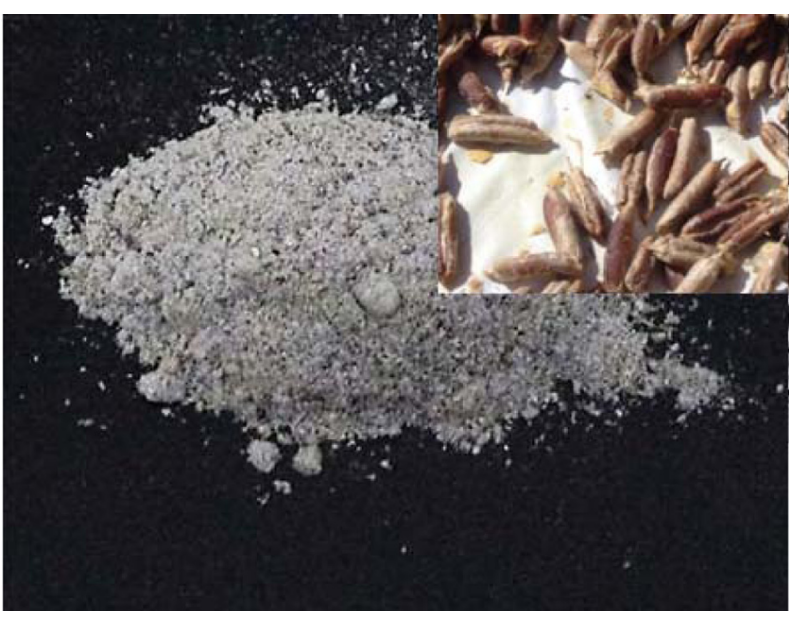

Fig. 3. Date seed ash (DSA); up-right-side: original date seed (Mirhosseini et al. 2016)

Table 2. Chemical composition of the three additives (\%)

\begin{tabular}{lccc}
\hline Composition & Siliceous & Limestone & DSA \\
\hline $\mathrm{SiO}_{2}$ & 74.5 & 4.1 & 58.6 \\
\hline $\mathrm{Al}_{2} \mathrm{O}_{3}$ & 9.8 & 6.2 & 4.9 \\
\hline $\mathrm{Fe}_{2} \mathrm{O}_{3}$ & 0.7 & 0.4 & 7.9 \\
\hline $\mathrm{CaO}$ & 2.1 & 69.7 & 4.8 \\
\hline $\mathrm{MgO}$ & 3.2 & 1.1 & 3.9 \\
\hline $\mathrm{Na}_{2} \mathrm{O}$ & - & - & 7.2 \\
\hline $\mathrm{K}_{2} \mathrm{O}$ & - & - & 0.3 \\
\hline $\mathrm{SO}_{3}$ & - & - & 0.4 \\
\hline $\mathrm{LOI}$ & 8.8 & 18.5 & 12 \\
\hline
\end{tabular}

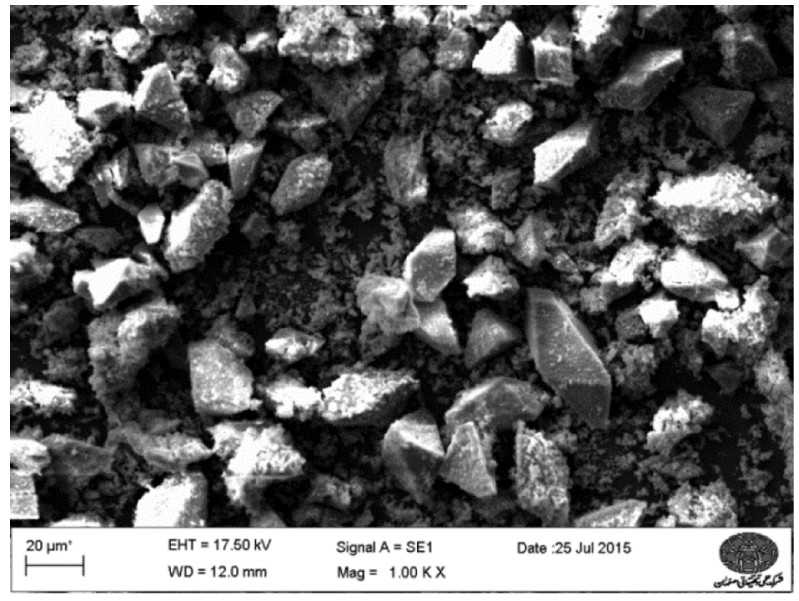

(a) DSA

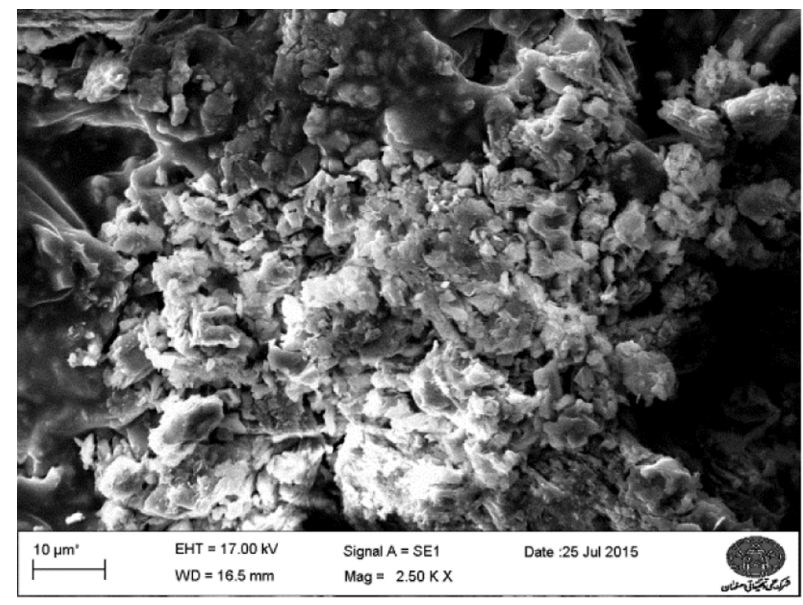

(b) siliceous additive

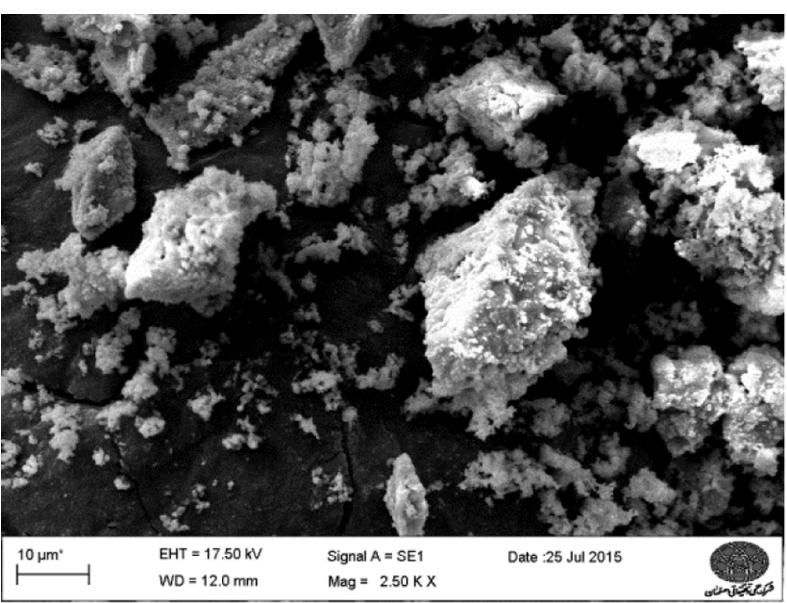

(c) limestone additive

Fig. 4. SEM images of the additives tested

Figure 4 presents the Scanning Electron Microscopy (SEM) pictures of the three additives tested. In this figure the granular grading and regular geometry of DSA particles can be observed. Additionally, XRF testing was carried out on these additives and their major constituents were determined as reported in Table 2. 


\section{Results and discussion}

\subsection{Asphalt binder}

\subsubsection{Stress-strain curves}

As it was mentioned earlier, before the modifications of the loading scheme in LAS testing, strains were applied on the specimens step wised. This type of loading has some disadvantages. For instance, the sudden increased loading amplitude leads to induced sudden increment in crack growth rates (Hintz, Bahia 2013). On the other hand at each stage, crack growth rate decreases and the rate does not correspond with fatigue crack propagation. This procedure results in decreased loading capacity and earlier failure of the specimen (Hintz, Bahia 2013). However, the analysis of cracks development in LAS testing is out of the scope of this research.

In this work, amplitude sweep testing was conducted on binders directly after the frequency sweep test. The results were analyzed using VECD approach. In this method the stress-strain and damage curves (resulted from VECD analysis) are plotted.

Figures 5 to 7 show stress-strain curves for bitumen binders containing the three additives used in this research. As it can be seen in Figure 5, for binders containing $3 \%, 6 \%$ and $9 \%$ siliceous additive (i.e. BS samples),

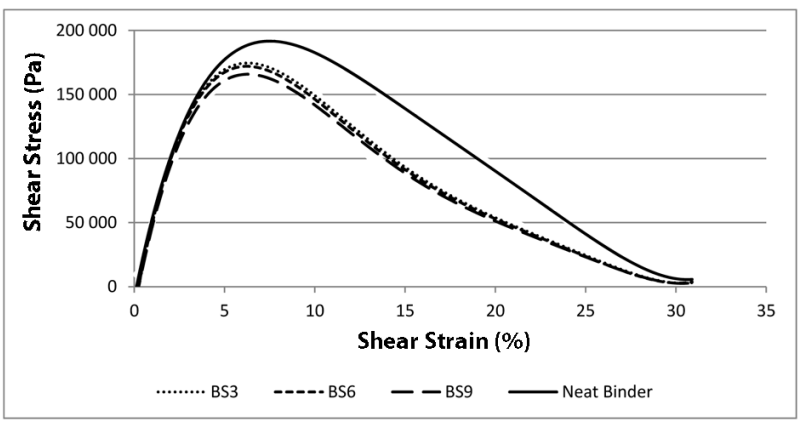

Fig. 5. Stress-strain curves extracted from LAS testing of siliceous modified binders

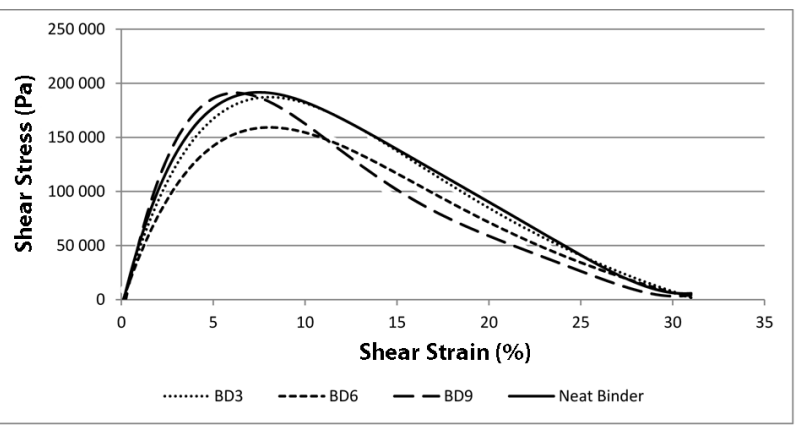

Fig. 6. Stress-Strain curves extracted from LAS testing of DSA modified binders

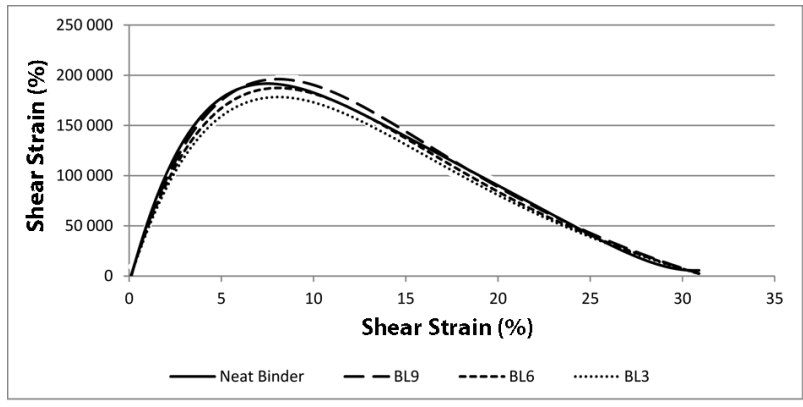

Fig. 7. Stress-Strain curves extracted from LAS testing of limestone modified binders

adding siliceous additive resulted in a considerable drop in maximum stress, compared with the neat binder. For instance, the maximum stress in BS9 was $170 \mathrm{kPa}$ which is $13 \%$ lower than that of the neat binder (being $194 \mathrm{kPa}$ ). Adding siliceous additive resulted in lower stresses. With regard to shear stresses, it can be realized that the ultimate presumed strain (i.e. 30\%) occurred earlier. This indicates that fatigue life of BS modified binder would be rather short.

With reference to Figure 6, it can be seen that there is no particular order in the trends of stress-strain curves for BD samples. BD9 experienced the highest maximum stress among all the other BD binders. In BS specimens, BS9 showed the lowest maximum stress. Mirhosseini et al. (2016) investigated the effects of various amounts of DSA on binders and concluded that chemical interactions exist between bitumen binders and DSA. The addition of DSA changed properties of the bitumen binders appreciably. With reference to Figure 6, it can be seen that sample BD3 experienced the maximum stress level of $188 \mathrm{kPa}$, while this parameter was recorded about 160 and $190 \mathrm{kPa}$ for BD6 and BD9 samples, respectively. Similarly, the stress-strain curves for binders containing limestone additive are reported in Figure 7. As it can be seen, similar behavior was observed on all samples containing this additive. For instance, the highest value of maximum stress belonged to BL9 (with $197 \mathrm{kPa}$ ). This is almost equal to that of the neat binder (with $194 \mathrm{kPa}$ ). Hence, it is expected that the fatigue behavior of BL samples could be considered similar to the neat binder. Also, the values of maximum shear stress for all samples are shown in Table 3.

\subsubsection{Damage characteristics and fatigue failure}

In addition to stress-strain curves, the damage curves can also be drawn from LAS testing results. Damage curves are plotted using excel file prepared by some researchers (Kavussi, Barghabany 2015). Damage intensity and material integrity at failure moment are the two key factors

Table 3. Values of shear stress for control and modified binders

\begin{tabular}{lllllllllll}
\hline Sample & Control & BS3 & BS6 & BS9 & BD3 & BD6 & BD9 & BL3 & BL6 & BL9 \\
\hline Stress $(\mathrm{Pa})$ & 194.3 & 179.7 & 176.4 & 170.8 & 196 & 160.4 & 187.8 & 188.8 & 179.8 & 197.8 \\
\hline
\end{tabular}


in investigating fatigue resistance of binders (Safaei et al. 2014). Figure 8 shows the difference between damage intensity of BD samples, compared with the neat control binder. As previously stated, a higher value of damage intensity at the moment of failure can indicate that the material has a high fatigue resistance (Safaei et al. 2014). With reference to Figure 8, it can be observed that BD3 has the lowest damage intensity, compared with that of the control and BD samples. Among the various modified binders, BD6 had the highest damage intensity. Therefore, it could be inferred that BD3 and BD6 have the lowest and the highest fatigue life among the four specimens. The complete details of damage characteristics and fatigue behavior of the investigated samples are reported in Table 4. For a better understanding of the phenomenon, the fatigue life cycles of the control and the modified binders at strain level of $2.5 \%$ are illustrated in Figure 9.

Table 4. Damage characteristics of binders after LAS testing

\begin{tabular}{lcccc}
\hline sample & $\begin{array}{c}\text { Dam- } \\
\text { age } \\
\text { level }\end{array}$ & \multicolumn{2}{c}{$\begin{array}{c}N_{f} \text { at strain } \\
\text { level of }\end{array}$} & Fatigue model \\
\cline { 3 - 4 } $\begin{array}{l}\text { Base } \\
\text { bitumen }\end{array}$ & 0.423 & 5889 & 820 & $N_{f}=7.9 \times 10^{4}\left(\gamma_{\max }\right)^{2.84}$ \\
\hline BS3 & 0.402 & 3795 & 562 & $N_{f}=4.74 \times 10^{4}\left(\gamma_{\max }\right)^{2.75}$ \\
\hline BS6 & 0.391 & 3601 & 525 & $N_{f}=4.59 \times 10^{4}\left(\gamma_{\max }\right)^{2.77}$ \\
\hline BS9 & 0.391 & 3545 & 517 & $N_{f}=4.51 \times 10^{4}\left(\gamma_{\max }\right)^{2.77}$ \\
\hline BL3 & 0.419 & 7767 & 1107 & $N_{f}=1.02 \times 10^{5}\left(\gamma_{\max }\right)^{2.81}$ \\
\hline BL6 & 0.482 & 9144 & 1273 & $N_{f}=1.24 \times 10^{5}\left(\gamma_{\max }\right)^{2.84}$ \\
\hline BL9 & 0.430 & 7930 & 1130 & $N_{f}=1.04 \times 10^{5}\left(\gamma_{\max }\right)^{2.81}$ \\
\hline BD3 & 0.425 & 7757 & 1105 & $N_{f}=1.01 \times 10^{5}\left(\gamma_{\max }\right)^{2.81}$ \\
\hline BD6 & 0.425 & 8003 & 1116 & $N_{f}=1.08 \times 10^{5}\left(\gamma_{\max }\right)^{2.84}$ \\
\hline & 0.402 & 3939 & 570 & $N_{f}=5.06 \times 10^{4}\left(\gamma_{\max }\right)^{2.78}$ \\
\hline
\end{tabular}

As it can be seen, the fatigue models for all specimens are developed based on VECD analysis. Fatigue life cycle value for each specimen at strain level of $2.5 \%$ is shown in Figure 9. It can be recognized that among all the samples, the one containing $6 \%$ limestone additive resulted in a 55\% increase in fatigue life, compared with the control binder. A decreasing trend was observed in BS samples. In this case, the modified binder containing $9 \%$ siliceous additive had a fatigue life of some $40 \%$ lower than that of the control binder. Therefore, it can be concluded that the siliceous modified binder has a reduced fatigue life compared with the control binder. This

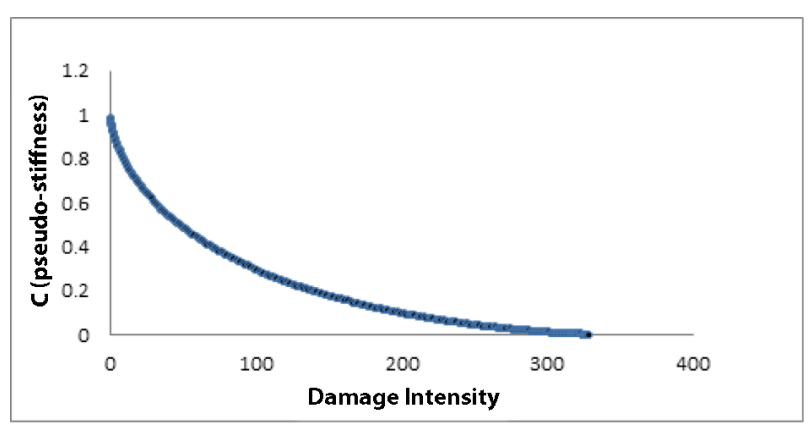

(a) BD3 sample

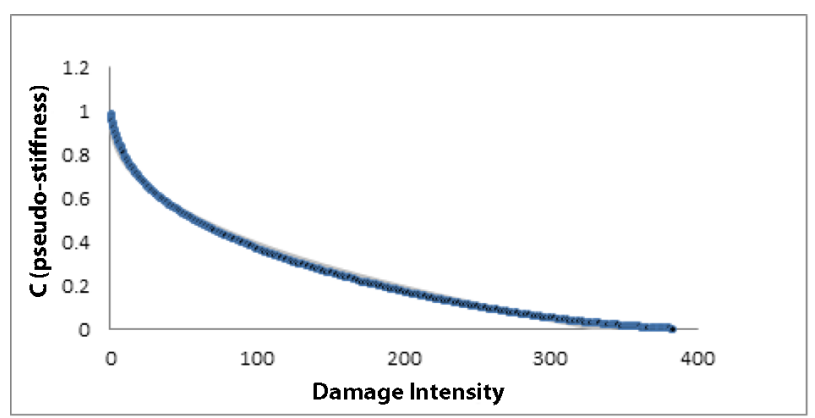

(b) BD6 sample

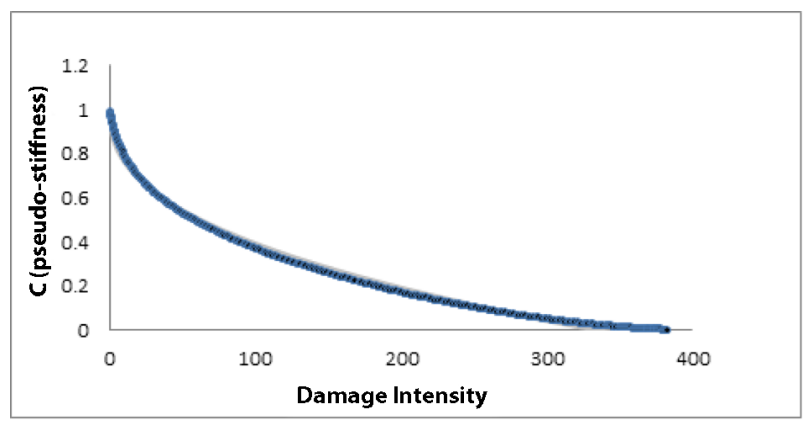

(c) BD9 sample

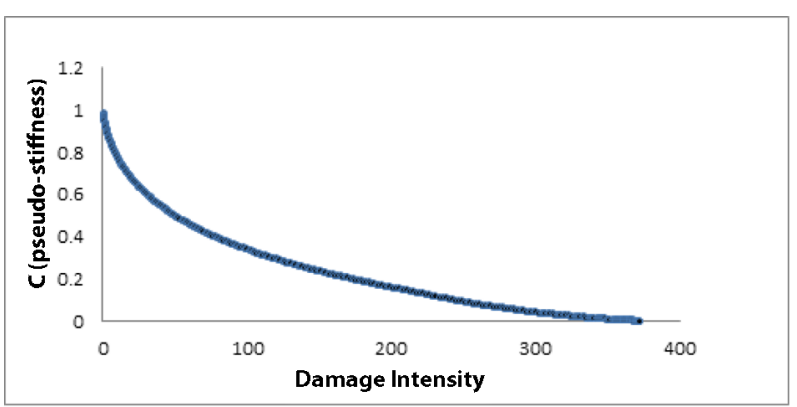

(d) Control neat binder

Fig. 8. VECD damage curves drawn from amplitude sweep testing data 


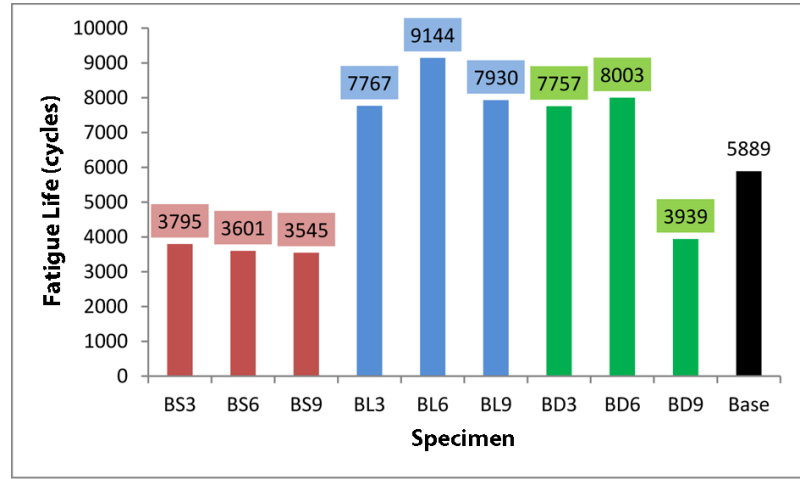

Fig. 9. Fatigue life of various modified binders at strain level of $2.5 \%$

might be due to the higher stiffness of BS samples. The mix with higher stiffness is more prone to fatigue failure (Hinislioğlu et al. 2005; Bagampadde et al. 2013). Increasing the amount of $\mathrm{SiO}_{2}$ or additives containing high percent of Silicon to bitumen would enhance stiffness of the binders (Sadeghpour et al. 2015; Shafabakhsh, Ani 2015; Rusbintardjo et al. 2013). The main reason for that were $\mathrm{SiO}_{2}$ molecules and this growth occurred through crosslinking process. The silicon molecules cross-linked between asphalt binder molecules when siliceous additive was entered into the binder mass. This results in a dense and hard material with high cross-link density (Aziz et al. 2003). In the case of BL samples, the highest fatigue life was achieved in BL6. Fatigue life of BL samples was first increased to 7767; then it was increased to 9144 and then decreased to 7930. Results showed that with adding limestone to bitumen in the investigated range, improved fatigue life will be observed. Finally, investigating the effects of DSA on fatigue behavior of BD samples showed that the maximum amount of DSA to improve fatigue life of binder is $6 \%$ by weight of bitumen. As it can be seen, BD6 showed the maximum tolerance in fatigue behavior among all BD samples (with $36 \%$ greater fatigue life than the control binder). However, increased amounts of DSA resulted in significantly reduced fatigue life of the DSA containing binder. Utilizing regression analysis resulted in determining optimum values of limestone and DSA in their resistance to fatigue failure. The values were $6.1 \%$ and $4.6 \%$ for limestone and DSA additive, respectively.

\subsection{Asphalt mixtures testing results}

\subsubsection{ITSM results}

Results of ITSM testing are reported in Figure 10. For each sample, three specimens were prepared and each specimen was tested twice under two different conditions as described above. It can be seen from this figure that stiffness modulus values were decreased with increased stress level. At a same stress level, stiffness modulus of BS samples are greater than that of limestone and DSA modified samples.

With reference to Figure 10, an increase in stiffness modulus of BS and BD specimens can be observed with

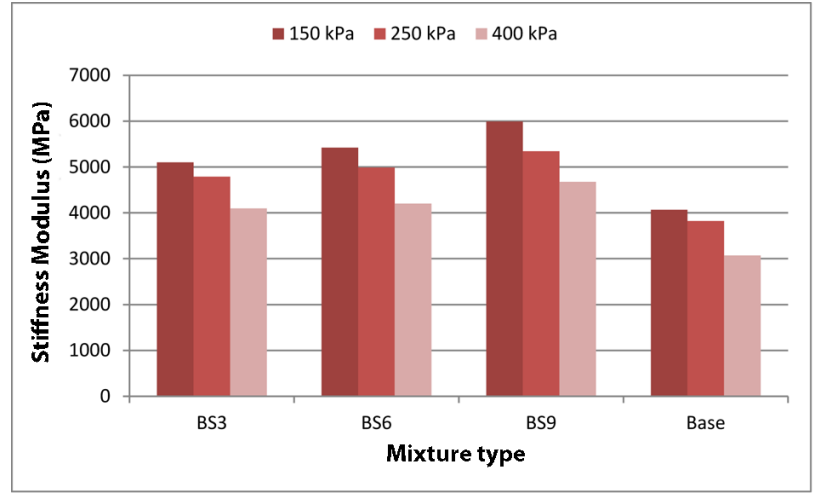

(a) Siliceous modified mixes

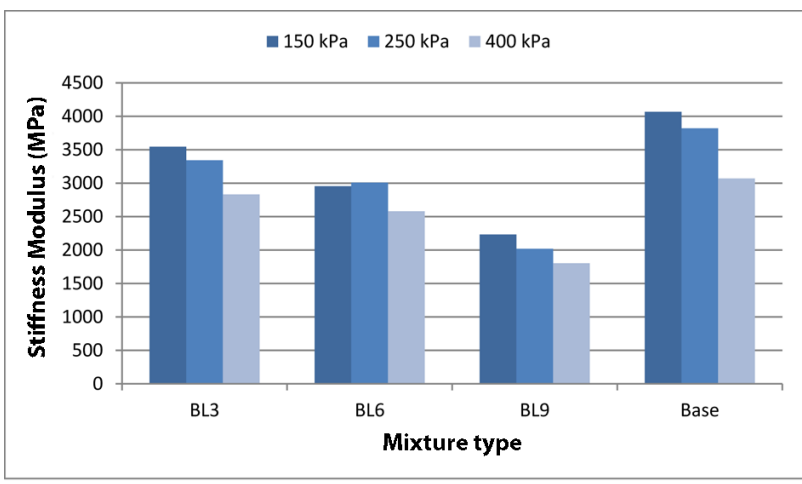

(b) Limestone modified mixes

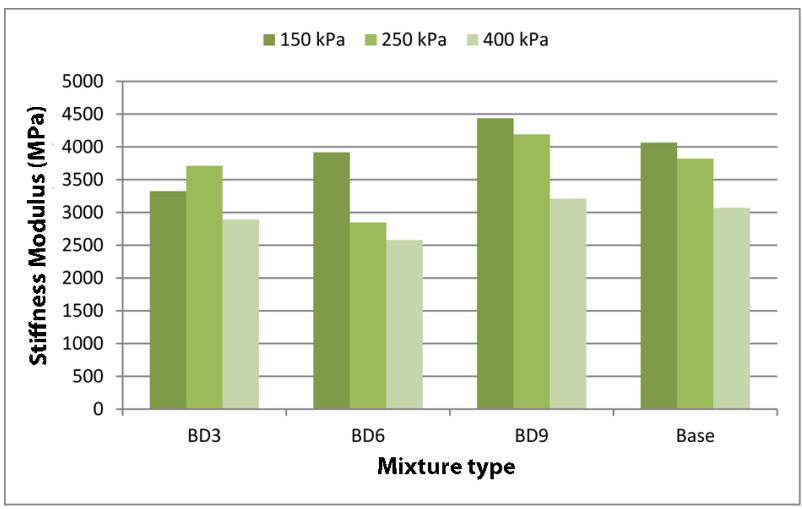

(c) DSA modified mixes

Fig. 10. Stiffness modulus of various modified mixes

increasing additive amounts. In contrast, BL samples experienced a decreasing trend with increased amounts of the additive. Another important issue is that the increased stress level with result in decreased stiffness modulus. Generally, stiffness modulus of BS samples are greater than that of the other BL samples. The highest value of belonged to BS9 with $5994 \mathrm{kPa}$ at stress level of $150 \mathrm{kPa}$. While the lowest value was attributed to BL9 sample at stress level of $400 \mathrm{kPa}$ (with $1803 \mathrm{kPa}$ ). Stiffness values of $\mathrm{BD}$ samples varied from below to above the control specimen. values of $\mathrm{BD} 3$ and $\mathrm{BD} 6$ specimens were lower than the stiffness modulus of the control specimen 
Table 5. ITFT fatigue testing results of mixes containing various amounts of additives

\begin{tabular}{|c|c|c|c|c|c|}
\hline Sample & $\sigma(\mathrm{kPa})$ & $\varepsilon\left(\times 10^{-6}\right)$ & $N_{f}$ & Fatigue model & $R^{2}$ \\
\hline \multirow{3}{*}{ Control } & 150 & 75 & 6338 & \multirow{3}{*}{$N_{f}=5 \mathrm{E}+06 \varepsilon^{-1.512}$} & \multirow{3}{*}{0.94} \\
\hline & 250 & 134 & 3285 & & \\
\hline & 400 & 166 & 1760 & & \\
\hline \multirow{3}{*}{$\mathrm{BS} 3$} & 150 & 60 & 4213 & \multirow{3}{*}{$N_{f}=1 \mathrm{E}+06 \varepsilon^{-1.402}$} & \multirow{3}{*}{0.95} \\
\hline & 250 & 107 & 2199 & & \\
\hline & 400 & 125 & 1394 & & \\
\hline \multirow{3}{*}{ BS6 } & 150 & 56 & 3942 & \multirow{3}{*}{$N_{f}=895547 \varepsilon^{-1.341}$} & \multirow{3}{*}{0.96} \\
\hline & 250 & 102 & 2038 & & \\
\hline & 400 & 122 & 1302 & & \\
\hline \multirow{3}{*}{ BS9 } & 150 & 51 & 3773 & \multirow{3}{*}{$N_{f}=689330 \varepsilon^{-1.319}$} & \multirow{3}{*}{0.96} \\
\hline & 250 & 95 & 1903 & & \\
\hline & 400 & 109 & 1287 & & \\
\hline \multirow{3}{*}{ BL3 } & 150 & 86 & 6952 & \multirow{3}{*}{$N_{f}=745338 \varepsilon^{-1.047}$} & \multirow{3}{*}{0.98} \\
\hline & 250 & 152 & 4065 & & \\
\hline & 400 & 181 & 3109 & & \\
\hline \multirow{3}{*}{ BL6 } & 150 & 104 & 8136 & \multirow{3}{*}{$N_{f}=1 \mathrm{E}+07 \varepsilon^{-1.588}$} & \multirow{3}{*}{0.95} \\
\hline & 250 & 170 & 4338 & & \\
\hline & 400 & 198 & 2745 & & \\
\hline \multirow{3}{*}{ BL9 } & 150 & 137 & 9121 & \multirow{3}{*}{$N_{f}=2 \mathrm{E}+07 \varepsilon^{-1.535}$} & \multirow{3}{*}{0.89} \\
\hline & 250 & 253 & 4617 & & \\
\hline & 400 & 284 & 2554 & & \\
\hline \multirow{3}{*}{ BD3 } & 150 & 92 & 6892 & \multirow{3}{*}{$N_{f}=4 \mathrm{E}+07 \varepsilon^{-1.93}$} & \multirow{3}{*}{0.97} \\
\hline & 250 & 138 & 3676 & & \\
\hline & 400 & 177 & 1898 & & \\
\hline \multirow{3}{*}{ BD6 } & 150 & 78 & 7115 & \multirow{3}{*}{$N_{f}=633154 \varepsilon^{-1.024}$} & \multirow{3}{*}{0.82} \\
\hline & 250 & 180 & 3992 & & \\
\hline & 400 & 198 & 2241 & & \\
\hline \multirow{3}{*}{ BD9 } & 150 & 69 & 5921 & \multirow{3}{*}{$N_{f}=4 \mathrm{E}+06 \varepsilon^{-1.541}$} & \multirow{3}{*}{0.94} \\
\hline & 250 & 122 & 3111 & & \\
\hline & 400 & 159 & 1532 & & \\
\hline
\end{tabular}

and BD9 showed higher values at all three stress levels. Increasing stiffness of BS and BD asphalt mixes with increasing the amount of additive might be due to the considerable amount of silicon in their structure. As mentioned before, increasing the amount of $\mathrm{SiO}_{2}$ or additives containing high percent of Silicon to the mix will stiffen the blend and consequently, the stiffness modulus of the mix will be increased. Besides, as a result of increasing the stiffness modulus of asphalt binder, the adhesion between the aggregates enhances and materials of the mixture can sorely slid. Therefore, the stiffness modulus of the mixture will grow significantly (Arabani, Tahami 2017).

\subsubsection{ITFT results}

The number of cycles to failure and final strain of asphalt mixtures at different stress levels are reported in
Table 5. Generally, it can be observed that with increasing level of the applied stress, fatigue life of the specimens are reduced and the final strains are increased. The table shows that mixtures made with limestone modified binders resulted in a greater fatigue life. Assessing the role of DSA on HMA mixes, shows that the addition of $6 \%$ DSA to a mix results in good fatigue life resistance. However, with increasing the amounts of DSA to greater values, considerable decrease in fatigue life results. For instance, at stress level of $150 \mathrm{kPa}$, the addition of 3 and $6 \%$ DSA to bitumen resulted in 8 and $12 \%$ increase in fatigue life, respectively. The addition of DSA to bitumen at low levels (i.e. below 6\%) will gradually break the structure of bitumen. Then sodium and calcium salts are formed which have more adhesion properties in sticking aggregates together, compared with the control specimens (Mirhosseini et al. 2016). In the case of siliceous 
samples, there will be a reduced trend in fatigue life of mixes with increasing percentages of siliceous additive. As an example, the addition of $3 \%$ siliceous additive to bitumen in BS mixes at stress level of $250 \mathrm{kPa}$, resulted in $33 \%$ reduced fatigue life of HMA mixes. On the other hand, fatigue behavior of BL mixes were all improved in the ranges of the studied values. For example, the addition of $9 \%$ limestone additive at stress level of $400 \mathrm{kPa}$ improved fatigue life of mixes up to $44 \%$ (compared with the control mix).

\subsection{Correlation equations}

Three relationships were developed, based on fatigue coefficients of the modified binders and asphalt mixes. The models are reported in Table 6. Based on $R^{2}$ coefficients reported in Table 6, it can be seen that the predicted model of BS samples can precisely relate the fatigue life of modified binders to those in their HMA mixes. However, $R^{2}$ value of BL samples could be considered acceptable but the model developed for BD samples seems to be unreliable to link fatigue parameters to each other.

Table 6. Correlation equations relating fatigue behavior of binders and HMA mixes

\begin{tabular}{ccc}
\hline Sample type & Regression equation & $R^{2}$ \\
\hline BS & $N_{f}=0.4798 \ln (\varepsilon)-7.9103$ & 0.98 \\
BL & $N_{f}=0.2558 \ln (\varepsilon)-5.5691$ & 0.57 \\
BD & $N_{f}=0.1809 \ln (\varepsilon)-4.5656$ & 0.37 \\
\hline
\end{tabular}

\section{Conclusions}

Based on the results obtained from using Date Seed Ash in an asphalt mix and investigating the role of two different additive types in mixes, the following conclusions can be drawn:

1. Application of DSA as a bitumen modifier improves fatigue behavior of both bitumen and asphalt mixes to a good extend.

2. Based on LAS testing results, siliceous additive decreased fatigue resistance of bitumen. In contrast, limestone additive increased fatigue life of bitumen to some $12 \%$. With this regard, the addition of $3 \%$ and $6 \%$ of limestone additive to asphalt mix resulted to increased fatigue life of mixes up to $32 \%$ and $55 \%$, respectively.

3. Evaluating the effects of DSA on fatigue life of bitumen showed that there was a peak in the trend. Regression analysis of LAS testing data yielded to an optimum value of $4.6 \%$ of the weight of bitumen in order to achieve a better behavior against fatigue failure.

4. ITFT results showed that siliceous additive had a detrimental effect on fatigue life of asphalt mixes. At stress level of $150 \mathrm{kPa}$, for example, the addition of $3 \%$ and $9 \%$ siliceous additive to bitumen, resulted in $33 \%$ and $40 \%$ decrease in fatigue life of mixes, respectively.

5. Similar to LAS testing, with adding DSA to an asphalt mix, its fatigue life will first increase, and then it will decrease. Hence, an optimum amount of DSA should be determined to be added to HMA mixtures.

6. Regression models were developed, based on fatigue coefficients in logarithmic scale in order to show a meaningful relationship between fatigue properties of bitumen and that of asphalt mixes. However, a logical relationship between fatigue behavior of modified bitumen and HMA mixes could not be established. The sources of errors or uncertainties of precisions in performing laboratory tests might have caused this incompatibility.

\section{Disclosure statement}

No potential conflict of interest was reported by the authors.

\section{References}

Al-Khateeb, G.; Shenoy, A. 2004. A distinctive fatigue failure criterion, Journal of the Association of Asphalt Paving Technologists 73: 585-622.

American Association of State Highway and Transportation Officials (AASHTO). 1993. AASHTO guide for design of pavement structures, Vol. 1. AASHTO.

AASHTO - TP31 Standard test method for determining the resilent modulus of bituminous mixtures by indirect tension. AASHTO, 1996.

AASHTO - TP101. Estimating damage tolerance of asphalt binders using the linear amplitude sweep. AASHTO, 2014.

ASTM D 6927 Standard test method for Marshall stability and flow... ASTM International

Andriescu, A.; Iliuta, S.; Hesp, S. A. M.; Youtcheff, J. S. 2004. Essential and plastic works of ductile fracture in asphalt binders and mixtures, in Proceedings of the Forty-Ninth Annual Conference of the Canadian Technical Asphalt Association (CTAA), 2004, Montreal, Quebec.

Arabani, M.; Mirabdolazimi, S. M. 2011. Experimental investigation of the fatigue behavior of asphalt concrete mixtures containing waste iron powder, Materials Science and Engineering: A 528(10): 3866-3870.

https://doi.org/10.1016/j.msea.2011.01.099

Arabani, M.; Tahami, S. A. 2017. Assessment of mechanical properties of rice husk ash modified asphalt mixture, Construction and Building Materials 149: 350-358. https://doi.org/10.1016/j.conbuildmat.2017.05.127

Arabani, M.; Tahami, S. A.; Hamedi, G. H. 2017a. Performance evaluation of dry process crumb rubber-modified asphalt mixtures with nanomaterial, Road Materials and Pavement Design, 1-18. https://doi.org/10.1080/14680629.2017.1302356

Arabani, M.; Tahami, S. A.; Taghipoor, M. 2017b. Laboratory investigation of hot mix asphalt containing waste materials, Road Materials and Pavement Design 18(3): 713-729. https://doi.org/10.1080/14680629.2016.1189349

Azarhoosh, A. R.; Nejad, F. M.; Khodaii, A. 2016. Nanomaterial and fatigue cracking of hot mix asphalt, Road Materials and Pavement Design, 1-14. https://doi.org/10.1080/14680629.2016.1261724

Aziz, T.; Waters, M.; Jagger, R. 2003. Analysis of the properties of silicone rubber maxillofacial prosthetic materials, 
Journal of Dentistry 31(1): 67-74.

https://doi.org/10.1016/S0300-5712(02)00084-2

Bagampadde, U.; Kaddu, D.; Kiggundu, B. M. 2013. Evaluation of rheology and moisture susceptibility of asphalt mixtures modified with low density polyethylene, International Journal of Pavement Research and Technology 6(3): 217-224.

Bahia, H. U.; Hanson, D. I.; Zeng, M.; Zhai, H.; Khatri, M. A.; Anderson, R. M. 2001a. Characterization of modified asphalt binders in superpave mix design. No. Project 9-10 FY'96.

Bahia, H. U.; Zhai, H.; Zeng, M.; Hu, Y.; Turner, P. $2001 \mathrm{~b}$. Development of binder specification parameters based on characterization of damage behavior (with discussion), Journal of the Association of Asphalt Paving Technologists 70: 442-470.

Capitão, S. D.; Picado-Santos, L. G.; Martinho, F. 2012. Pavement engineering materials: Review on the use of warmmix asphalt, Construction and Building Materials 36: 1016-1024. https://doi.org/10.1016/j.conbuildmat.2012.06.038

Chandrasekaran, M.; Bahkali, A. H. 2013. Valorization of date palm (Phoenix dactylifera) fruit processing by-products and wastes using bioprocess technology-Review, Saudi Journal of Biological Sciences 20(2): 105-120. https://doi.org/10.1016/j.sjbs.2012.12.004

Chen, J. S.; Liao, M. C.; Shiah, M. S. 2002. Asphalt modified by styrene-butadiene-styrene triblock copolymer: Morphology and model, Journal of Materials in Civil Engineering 14(3): 224-229. https://doi.org/10.1061/(ASCE)0899-1561(2002)14:3(224)

Cuadri, A. A.; Partal, P.; Ahmad, N.; Grenfell, J.; Airey, G. 2015. Chemically modified bitumens with enhanced rheology and adhesion properties to siliceous aggregates, Construction and Building Materials 93: 766-774. https://doi.org/10.1016/j.conbuildmat.2015.05.098

Daniel, J. S.; Kim, Y. R. 2002. Development of a simplified fatigue test and analysis procedure using a viscoelastic, continuum damage model (with discussion), Journal of the Association of Asphalt Paving Technologists 71: 619-650.

Deacon, J. A.; Harvey, J. T.; Tayebali, A.; Monismith, C. L. 1997. Influence of binder loss modulus on the fatigue performance of asphalt concrete pavements, Journal of the Association of Asphalt Paving Technologists 66: 633-668.

EN-12697-24 Bituminous mixtures-test methods for hot mix asphalt-Part 24-Resistance to fatigue. European Standard, 2004.

Food, F. A. O. 2015. Fao stat: Agriculture data. Agriculture organization of the United Nations statistics division.

Hinislioğlu, S.; Aras, H. N.; Bayrak, O. Ü. 2005. Effects of high density polyethylene on the permanent deformation of asphalt concrete, IJEMS 12(5): 456-460.

Hintz, C.; Bahia, H. 2013. Simplification of linear amplitude sweep test and specification parameter, Transportation Research Record: Journal of the Transportation Research Board 2370: 10-16.

Hintz, C.; Velasquez, R.; Johnson, C.; Bahia, H. 2011a. Modification and validation of linear amplitude sweep test for binder fatigue specification, Transportation Research Record: Journal of the Transportation Research Board 2207: 99-106. https://doi.org/10.3141/2370-02

Hintz, C.; Velasquez, R.; Li, Z.; Bahia, H. 2011b. Effect of oxidative aging on binder fatigue performance, Journal of the Association of Asphalt Paving Technologists 80: 527-548. https://doi.org/10.3141/2207-13

Isacsson, U.; Xiaohu, L. 1999. Laboratory investigation of polymer modified bitumens, Journal of the Association of Asphalt Paving Technologists 68: 35-63.

Johnson, C.; Bahia, H.; Wen, H. 2009. Practical application of viscoelastic continuum damage theory to asphalt binder fatigue characterization, Journal of the Association of Asphalt Paving Technologists 78: 597-638.

Kavussi, A.; Barghabany, P. 2015. Investigating fatigue behavior of nanoclay and nano hydrated lime modified bitumen using LAS test, Journal of Materials in Civil Engineering 28(3), 04015136. https://doi.org/10.1061/(ASCE)MT.1943-5533.0001376

Khattak, M. J.; Khattab, A.; Rizvi, H. R. 2013. Characterization of carbon nano-fiber modified hot mix asphalt mixtures, Construction and Building Materials 40: 738-745. https://doi.org/10.1016/j.conbuildmat.2012.11.034

Köfteci, S.; Ahmedzade, P.; Kultayev, B. 2014. Performance evaluation of bitumen modified by various types of waste plastics, Construction and Building Materials 73: 592602. https://doi.org/10.1016/j.conbuildmat.2014.09.067

Kutay, M. E.; Gibson, N. H.; Youtcheff, J. 2008. Conventional and viscoelastic continuum damage (VECD)-based fatigue analysis of polymer modified asphalt pavements (with discussion), Journal of the Association of Asphalt Paving Technologists 77: 395-434.

Lee, H. J.; Kim, Y. R. 1998. Viscoelastic continuum damage model of asphalt concrete with healing, Journal of Engineering Mechanics 124(11): 1224-1232.

https://doi.org/10.1061/(ASCE)0733-9399(1998)124:11(1224)

Martona, W.; Bahia, H. U. 2003. Defining asphalt binder fatigue as a function of pavement temperature and pavement structure, in TRB Report. USA, 41-62.

Martona, W.; Bahia, H. U. 2008. Developing a surrogate test for fatigue of asphalt binders, in Transportation Research Board 87 $7^{\text {th }}$ Annual Meeting. No. 08-1356.

Mirhosseini, S. F.; Khabiri, M. M.; Kavussi, A.; Kamali, M. J. 2016. Applying surface free energy method for evaluation of moisture damage in asphalt mixtures containing date seed ash, Construction and Building Materials 125: 408416. https://doi.org/10.1016/j.conbuildmat.2016.08.056

Modarres, A. 2013. Investigating the toughness and fatigue behavior of conventional and SBS modified asphalt mixes, Construction and Building Materials 47: 218-222.

https://doi.org/10.1016/j.conbuildmat.2013.05.044

Norouzi, A.; Kim, Y. R. 2015. Mechanistic evaluation of fatigue cracking in asphalt pavements, International Journal of Pavement Engineering 18(6): 530-546. https://doi.org/10.1080/10298436.2015.1095909

Read, J.; Whiteoak, D. 2003. The shell bitumen handbook. Thomas Telford.

Rusbintardjo, G.; Hainin, M. R.; Yusoff, N. I. M. 2013. Fundamental and rheological properties of oil palm fruit ash modified bitumen, Construction and Building Materials 49: 702-711.

https://doi.org/10.1016/j.conbuildmat.2013.08.056

Sabouri, M.; Kim, Y. 2014. Development of a failure criterion for asphalt mixtures under different modes of fatigue loading, Transportation Research Record: Journal of the Transportation Research Board 2447: 117-125. https://doi.org/10.3141/2447-13

Sadeghpour Galooyak, S.; Palassi, M.; Goli, A.; Zanjirani Farahani, H. 2015. Performance evaluation of nano-silica modified bitumen, International Journal of Transportation Engineering 3(1): 55-66.

Safaei, F.; Castorena, C.; Kim, Y. R. 2016. Linking asphalt binder fatigue to asphalt mixture fatigue performance using viscoelastic continuum damage modelling, Mechanics of Time-Dependent Materials 20(3): 299-323. https://doi.org/10.1007/s11043-016-9304-1

Safaei, F.; Lee, J. S.; Nascimento, L. A. H. D.; Hintz, C.; Kim, Y. R. 2014. Implications of warm-mix asphalt on longterm oxidative ageing and fatigue performance of asphalt binders and mixtures, Road Materials and Pavement Design 15(sup1): 45-61. 
Schapery, R. A. 1990. A theory of mechanical behavior of elastic media with growing damage and other changes in structure, Journal of the Mechanics and Physics of Solids 38(2): 215-253. https://doi.org/10.1016/0022-5096(90)90035-3

Shafabakhsh, G. H.; Ani, O. J. 2015. Experimental investigation of effect of Nano TiO 2/SiO 2 modified bitumen on the rutting and fatigue performance of asphalt mixtures containing steel slag aggregates, Construction and Building Materials 98: 692-702.

Shafabakhsh, G.; Taghipoor, M.; Sadeghnejad, M.; Tahami, S. A. 2015. Evaluating the effect of additives on improving asphalt mixtures fatigue behaviour, Construction and Building Materials 90: 59-67.

Sybilski, D.; Bańkowski, W. 2002. Asphalt pavement design using results of laboratory fatigue tests of asphalt mixtures, Road Materials and Pavement Design 3(2): 183-194. https://doi.org/10.1080/14680629.2002.9689921

Tsai, B. W.; Monismith, C. L.; Dunning, M.; Gibson, N.; D'Angelo, J.; Leahy, R.; King, G.; Christensen, D.; Anderson, D.; Davis, R.; Jones, D. 2005. Influence of asphalt binder properties on the fatigue performance of asphalt concrete pavements, Journal of the Association of Asphalt Paving Technologists 74: 733-789.

Underwood, B. S.; Kim, Y. R.; Guddati, M. N. 2010. Improved calculation method of damage parameter in viscoelastic continuum damage model, International Journal of Pavement Engineering 11(6): 459-476. https://doi.org/10.1080/10298430903398088

Whiteoak, D. 1990. The shell bitumen handbook. $4^{\text {th }}$ ed. Surrey, Shell Bitumen.

Yang, X.; You, Z.; Dai, Q.; Mills-Beale, J. 2014. Mechanical performance of asphalt mixtures modified by bio-oils derived from waste wood resources, Construction and Building Materials 51: 424-431. https://doi.org/10.1016/j.conbuildmat.2013.11.017

Yildirim, Y. 2007. Polymer modified asphalt binders, Construction and Building Materials 21(1): 66-72. https://doi.org/10.1016/j.conbuildmat.2005.07.007

Zhou, F.; Mogawer, W.; Li, H.; Andriescu, A.; Copeland, A. 2012. Evaluation of fatigue tests for characterizing asphalt binders, Journal of Materials in Civil Engineering 25(5): 610-617. https://doi.org/10.1061/(ASCE)MT.1943-5533.0000625

Ali FOROUTAN MIRHOSSEINI. Is PhD Candidate and Research Assistant at the Department of Civil and Environmental Engineering of Norwegian University of Science and Technology (NTNU), Trondheim, Norway. He has started PhD program this month (Oct 2017) at NTNU and received master's degree from Yazd University in 2016. He is author and co-author of about 5 scientific papers. Some parts of this research are derived from his master's thesis. Research interests include asphalt pavements, bitumen modification, HMA performance and also geometric road design.

Amir KAVUSSI. Is Professor at the Faculty of Civil and Environmental Engineering of Tarbiat Modares University, Tehran, Iran. He received a PhD in Highway Engineering in 1989, University of Birmingham, England. He is author and co-author of more than 80 scientific papers. Research interests include pavement materials, design, management and maintenance.

Mohammad Hossain JALAL KAMALI. Is PhD Candidate at the Faculty of Civil and Environmental Engineering of Tarbiat Modares University, Tehran, Iran. He has started PhD program since 2014. He is author and co-author of about 10 scientific papers. Research interests include pavement materials, safety and abrasion resistance of concrete pavements.

Mohamad Mehdi KHABIRI. Is Associate Professor at the Department of Civil Engineering of Yazd University, Yazd, Iran. He received a PhD in Civil Engineering in 2008, Iran University of Science and Technology, Iran. He is author and co-author of more than 35 scientific papers. Research interests include flexible pavements, pavement materials, traffic safety and pavement maintenance.

Abolfazl HASSANI. Is Professor at the Faculty of Civil and Environmental Engineering of Tarbiat Modares University, Tehran, Iran. He received a PhD in Highway Engineering in 1992, University of Westminster, England. He is author and co-author of about 40 scientific papers. Research interests include pavement materials, flexible concrete pavements, rutting potential of flexible pavements and fibrous concrete. 